\title{
ONLINE LANGUAGE LEARNING TO DEVELOP ENGLISH READING AND LISTENING SKILLS IN UNIVERSITY STUDENTS: A PILOT STUY IN HONG KONG
}

\author{
Julia Chen ${ }^{1}$, Juliana Chau, Grace Lim, Voyce Li \\ Hong Kong Polytechnic University
}

\begin{abstract}
The range of technological applications in different educational contexts makes it necessary for continued inquiry into online language learning (OLL), especially in relation to its impact on different learner populations whose perception and acceptance of OLL can vary across settings. This pilot study involved 66 Chinese students in a Hong Kong university and examined their OLL experience in online reading and listening activities. Results of the study suggest the easy availability of internet resources can greatly enhance students' OLL experience, while raising four challenges in the areas of online materials development, student motivation, pedagogy-technology interface, and intercultural communicative competence. Possible ways of tackling such challenges are outlined. The article concludes with a view that successful OLL needs to be predicated on a tripartite framework of hardware, software and humanware.
\end{abstract}

KEY WORDS: Online language learning. Technology-enhanced language learning. English reading and listening skills.

\section{Introduction - Theoretical Framework}

The variety and quantity of affordable technologies in the last two decades have given impetus to the prevalence of online language learning (OLL) across educational contexts. Notable OLL-related learning benefits are documented in many studies that scrutinize reading (Murphy, 2007; Lysenko \& Abrami, 2014), listening (Hsu, Hwang, Chang, \& Chang, 2013), vocabulary (Wible, Liu, \& Tsao, 2011), and independent language learning (Chang, 2007), to name but a few. Lysenko and Abrami (2014), for instance, found that students' English reading comprehension skills showed significant improvements following the implementation of web-based applications. Similar gains in students' English listening proficiency were reported in Hsu et al.'s study (2013) where listening activities were mediated by handheld devices. Caution against over-generalization, however, is advised in other studies (e.g., Mollering \& Levy, 2012). They believe that the dynamic, multi-faceted nature of language learning where learner characteristics, learning context, task orientation and purpose, learner perception and expertise of technology, amongst others, can mediate the progress and success of language development.

There are three common modes of OLL delivery: web-facilitated, fully virtual, or blended, from which issues including the nexus between online learning and language acquisition, pedagogic design, perceived usefulness, patterns of use, and cases of success or otherwise, represent important foci of research in three main domains of computer-assisted language learning (CALL), namely, tutorial CALL, social computing CALL, and CALL gaming (Blake, 2011). The first two are much discussed, while the last advocates a computer gaming approach to language development by combining the characteristics of tutorial and social computing CALL.

${ }^{1}$ Corresponding author: Julia Chen julia.chen@polyu.edu.hk. English Language Centre, Hong Kong Polytechnic University, Hung Hom, Hong Kong (SAR), China. 
Tutorial CALL is known to be well-suited to the development of grammatical and lexical competencies through mechanical exercises, although such drills are criticized by some for being limited in interactivity and ability to foster meaning negotiation (Blake, 2011). This concern seems to have been mitigated by newer technological tools that offer innovative options for creating engaging online language tasks, like automatic individualized preemptive feedback and behaviour tracking systems, hence the term Intelligent CALL, or iCALL (Amaral \& Meurers, 2011). On the other hand, social computing CALL is employed mainly to harness the potential of social media that facilitates meaningful exchanges in text, audio or video format for language growth. Such a communication mode, be it synchronous or asynchronous, permits learners to assume greater agency than in traditional settings, thereby cultivating deeper communicative content (Hung \& Huang, 2015). As an emergent trend in CALL, game-mediated language learning is reported to have the virtue of promoting active engagement in negotiation to connect input, attention to language form and output in learner-centered situations, although this is a research area still in its infancy (PasfieldNeofitou, 2014).

\section{Rationale}

For all its merits, OLL awakens a number of concerns, as shown in a review of recent research-based studies in the field (Chau \& Lee, 2014). Chief among them is the limited generalizability of findings attributable to:

- the nature of research (generally small sample size, short duration)

- the methodology (mostly exploratory in design, involving user-report, overlapping role of researcher, teacher and developer)

- the researchers' constructs (possible over-zealous attitude and individual theoretical perspective affecting data analysis and interpretation)

While continuing examination of OLL-related issues has yielded promising outcomes, the range of technological applications in diverse learning milieux implies a need for further inquiry in OLL. This pilot study, therefore, aspires to construct a more nuanced understanding of how best OLL can be deployed to guide policy, pedagogy and practice, by considering its impact on a group of students in a Hong Kong university whose perception and acceptance of OLL may and can vary from that of their counterparts elsewhere.

This study was undertaken as an extension to a previous project conducted in 2010 that generated useful findings about Hong Kong (Chinese) secondary school students' English reading comprehension abilities as they prepared for the new Hong Kong Diploma of Secondary Education implemented in 2012 (Author ${ }^{2}$, Wu, Author ${ }^{1}, \&$ Lughmani, 2012). English is taught as a second or foreign language in Hong Kong. The Hong Kong Diploma of Secondary Education results are expressed in seven levels, namely, $5^{\star \star}, 5^{\star}, 5$, 4, 3, 2 and 1, with $5^{* \star}$ awarded to top-performing candidates. Student performance judged to fall below level 1 is designated as ' $U$ ' (Unclassified). The 2012/13 academic year saw the admission of the first cohort of students to Hong Kong universities based on their performance in the new examination. These entrants undergo a four-year degree curriculum, as distinct from the previous three-year structure.

We are English teachers at the Hong Kong Polytechnic University (PolyU). Findings from the previous secondary school project had informed the design and delivery of our new English curriculum for the new PolyU entrants. While a substantial proportion of PolyU undergraduate students (almost 80\% in 2013/14 and 2014/15) receive DSE scores of 4 or above in English, the number of those with lower scores (at Level 3 or below) is significant - about 60\% in 2013/14 and 2014/15 for sub-degree programmes. 
Initially, PolyU entrants with an examination score of 3 or below in English were required to complete credit-bearing English language enhancement subjects to ensure their English was adequate for university study in the English medium. This requirement, however, was discontinued in 2013/14 following changes to university policy. In response, we developed an online English learning platform on Blackboard, the PolyU Learning Management System, and piloted it in 2014/15, with language activities targeting reading and listening. Both skills are understood to occupy a crucial role in the transfer of knowledge in a broad range of learning situations (Goh, 2013; Hirvela, 2013). The online language activities are specifically designed to be short, snappy, and varied, with a time indicator for each activity to help students plan and pace learning in accordance with their schedule and needs. Instant online feedback, in the form of built-in answer key and brief explanatory notes, aims to promote self-evaluation and independent learning. In a certain sense, our online language activities can be classified as a type of iCALL in a completely virtual learning environment.

Included in the online language activities are two quizzes on the two language skills mentioned above. The two quizzes consist of the same set of questions, with randomized options for multiple choice items. The pre- and post-quizzes aim to help students identify areas of strength and limitation in language learning at university: the former as a diagnostic tool, and the latter as an indicator of the impact of the online language activities on student learning. The pilot study attracted more than 200 PolyU students from disciplines such as Marketing Management, Accounting and Finance, Biomedical Engineering and Electronic and Information Engineering in degree and sub-degree programmes.

\subsection{Objectives}

This article reports on the findings of a pilot study in the academic year 2014/15 that aimed to:

1) examine the impact of online language learning on Hong Kong (Chinese) university students' English reading and listening skills as inferred from the pre- and post-quizzes, and

2) identify key challenges associated with online language learning at university and possible ways to address them.

We argue that findings from the pilot study can direct language practitioners towards better appreciation of the shifting perspectives in the design and delivery of OLL, especially in the Hong Kong (Chinese) tertiary context. Space considerations preclude detailed discussion of the students' interaction with the full range of online activities developed for the pilot study. This article analyzes the data drawn primarily from the pre- and post-quizzes, which serve as artefacts to assist in the investigation of Hong Kong (Chinese) university students' OLL experience, rather than as evaluative devices to calibrate language competence.

\section{The Study}




\subsection{Context and participants}

Over 200 PolyU students participated voluntarily in the online language activities in the academic year 2014/15. Such students were enrolled in either undergraduate or sub-degree programmes across a range of academic disciplines, including Marketing Management, Accounting and Finance, Optometry, Nursing, Biomedical Engineering, Civil and Environmental Engineering, Electronic and Information Engineering, and Industrial System Engineering. The online activities, devised to provide supplemental English support for study at an English medium university, were made available to students through Blackboard, the PolyU learning management system. Because of the voluntary nature of participation, no pre-requisites applied. Participation did not lead to any grade points earned towards students' course requirements, a message which was conveyed to students at the outset of the pilot study. Our general understanding was that the participants' English was of reasonable proficiency, with some at the lower level.

\subsection{Online language activities}

The online English activities were modular in design, comprising 'learning input', 'activity/activities' and 'further learning resources'. The 15-, 30- and 45-minute time indicators showed the estimated amounts required to be spent on input and activity/activities in each module. The time indicators aimed to help students better manage their time while working on the activities (Fig. 1). In order to arouse and sustain students' interests in the activities, visual elements such as colours, images, diagrams, tables, charts, page layout, font size were employed creatively in the design of the modules. Vigorous efforts were made to secure permission from copyright owners for works that were not free. Visuals were used not only for their appeal but also for their potential educational value, such as using visual metaphors to enhance students' associative learning and thinking (Fig. 2). All modules contained further learning resources designed to provide students with additional practice exercises to enable them to continue their learning independently after finishing a module.

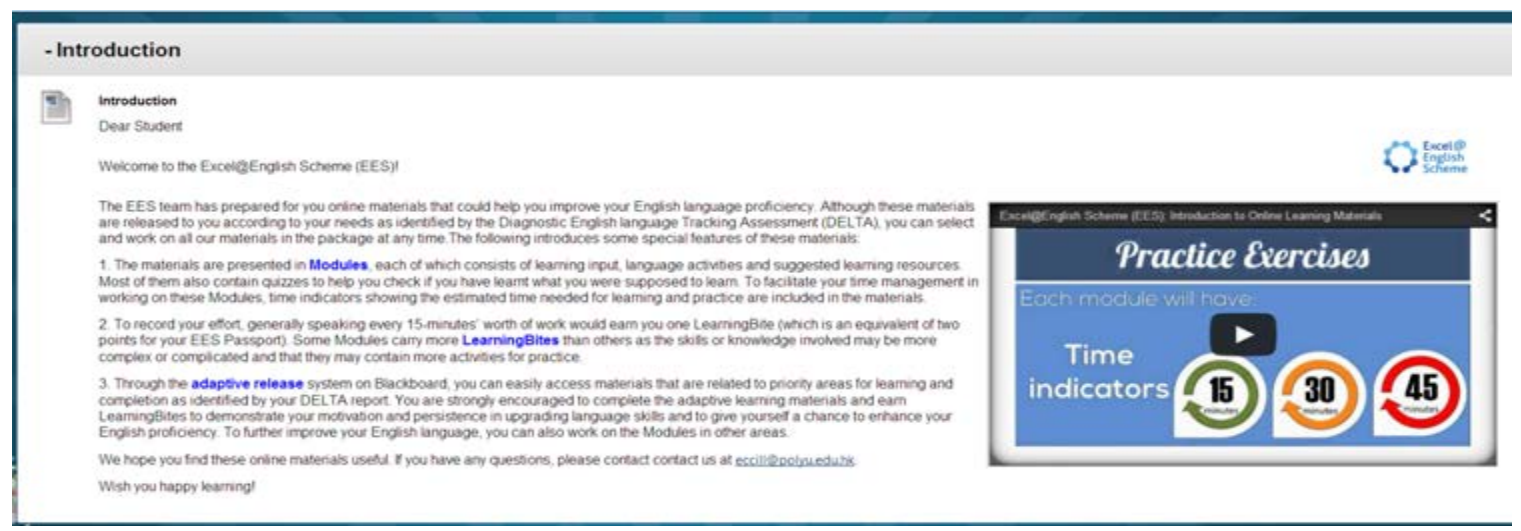

Figure 1. Online language activities: introduction page 


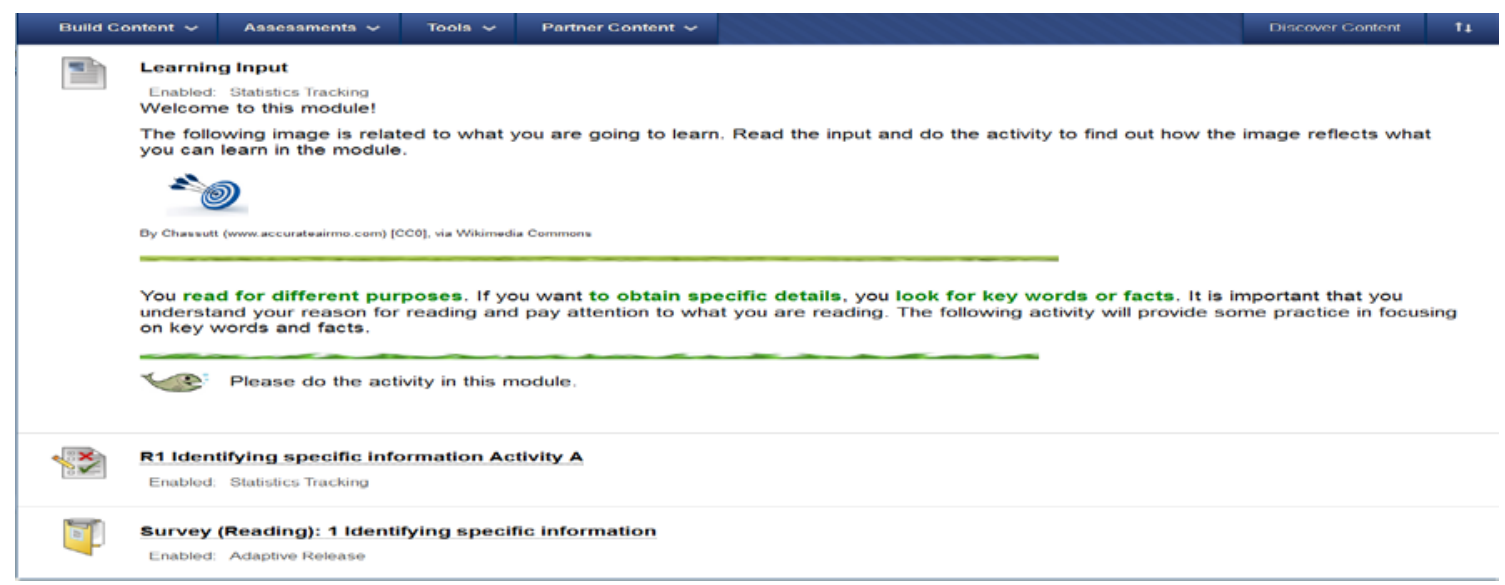

Figure 2. Sample online reading module

The reading and listening online activities targeted eight and six subskills respectively, in line with those discussed in the literature (e.g., Al-Musalli, 2015; Li \& Suen, 2013). In addition, two core reading skills and one listening core skill were included for less proficient students (Table 1). The categorization was intended to draw students' attention to the significance of such sub-skills in efficient comprehension while reading or listening. A variety of topics, deemed to match students' language ability and interest, were selected: social issues like democracy, child protection laws, sexual harassment; health-related discussion on food choice, sleep pattern; public speeches by well-known figures such as Martin Luther King, Michelle Obama, and J. K. Rowling.

Table 1. Reading and listening subskills

\begin{tabular}{|c|c|}
\hline Reading Subskills & Listening Subskills \\
\hline $\mathbf{R} \mathbf{1}$ Identifying specific information & L1 Identifying specific information \\
\hline $\begin{array}{l}\mathbf{R} \mathbf{2} \text { Interpreting a word or phrase as used by the } \\
\text { writer }\end{array}$ & $\begin{array}{l}\text { L2 Interpreting a word or phrase as used by the } \\
\text { speaker }\end{array}$ \\
\hline R3 Understanding main ideas and supporting ideas & L3 Understanding main ideas and supporting ideas \\
\hline $\begin{array}{l}\text { R4 Understanding information and making an } \\
\text { inference }\end{array}$ & $\begin{array}{l}\text { L4 Understanding information and making an } \\
\text { inference }\end{array}$ \\
\hline$R 5$ Inferring the writer's reasoning & L5 Inferring the speaker's reasoning \\
\hline $\boldsymbol{R} 6$ Interpreting an attitude or intention of the writer & L6 Interpreting an attitude or intention of the speaker \\
\hline $\begin{array}{l}R 7 \text { Understanding grammatical relationships of } \\
\text { words or phrases }\end{array}$ & \multirow{4}{*}{ Core Listening skill: Purpose of listening } \\
\hline $\boldsymbol{R} \mathbf{8}$ Identifying text type & \\
\hline $\begin{array}{l}\text { Core Reading Skill 1: Topic sentences and } \\
\text { supporting evidence }\end{array}$ & \\
\hline $\begin{array}{l}\text { Core Reading Skill 2: Structure of an essay and } \\
\text { Vvcabulary }\end{array}$ & \\
\hline Total no. of Modules: 13 & Total no. of Modules: 11 \\
\hline
\end{tabular}




\subsection{Instruments and procedures for data collection}

Table 2 shows that the pilot study ran from September 2014 to the end of June 2015, but its promotion, via email and face-to-face information sessions, started at the end of August 2014 before Semester 1 and in early January 2015 prior to Semester 2 to encourage student participation. The reading and listening activities could be accessed by students anywhere and at any time during the pilot study. The pre- and post-quizzes were administered in September 2014 and May/June 2015 respectively. The online survey (April/May 2015) and focus group interviews (May 2015) provided additional data to inform discussion and illuminate understanding.

Table 2. Implementation schedule of the pilot study

\begin{tabular}{|l|l|}
\hline Event & Timeline \\
\hline Promoting the online activities & August 2014, Semester 1 \\
\hline Completing the online pre-quiz & September 2014 \\
\hline Completing the online activities & September - December 2014 \\
\hline Promoting the online activities & January 2015, Semester 2 \\
\hline Completing the online activities & January - June 2015 \\
\hline Completing the online post-quiz & Mid-May - mid-June 2015 \\
\hline Completing the online questionnaire survey & April- May 2015 \\
\hline Conducting focus group interviews & May 2015 \\
\hline $\begin{array}{l}\text { Collecting and analyzing data } \\
\text { Compiling reports for dissemination }\end{array}$ & June - August 2015 \\
\hline
\end{tabular}

Qualitative and quantitative data for the pilot study were derived from:

(1) Online pre- and post-quizzes (Section 3.1)

- $\quad$ raw quiz scores

- student responses to questions - mainly the incorrect rate of each question

Students could attempt each quiz only once in 15 minutes and at one sitting. We took three steps to reduce the risk of cheating and memorization since feedback was immediately generated after each quiz. First, the two quizzes were conducted seven months apart. Second, students were not told that the same quiz would be administered as the post-quiz. Third, the set of options for multiple choice items was randomized.

(2) Focus group interviews (Appendix) 
- $\quad$ student responses to online language activities with respect to perceived usefulness, ease of navigability, and attitudinal change

Three focus group discussions were held, involving a total of 10 students who had attempted both the pre- and post-quizzes. Each discussion was audio-taped and lasted about 45 minutes. NVivo was employed to analyze the transcribed data.

(3) Online questionnaire survey (Fig. 6, Section 3.2.1)

- $\quad$ student responses to an online survey

175 students responded to the survey which asked them to describe their online language learning experience by clicking on the appropriate number on a scale from 1 (strongly disagree) to 4 (strongly agree). Students would click N/A to indicate a non-applicable statement.

\section{Results and discussion}

3.1 Objective 1: to examine the impact of online language learning on Hong Kong (Chinese) university students' English reading and listening skills as inferred from the pre- and post quizzes

Table 3 describes the total number of participants, the task items for each quiz, maximum possible scores, the overall mean and standard deviation.

Table 3. Quiz participants and raw scores

\begin{tabular}{|c|c|c|c|c|}
\hline & \multicolumn{2}{|c|}{ Reading } & \multicolumn{2}{|c|}{ Listening } \\
\hline & Pre-quiz & Post-quiz & Pre-quiz & Post-quiz \\
\hline No. of participants taking each quiz & 136 & 50 & 108 & 42 \\
\hline Question type and no. of questions & \multicolumn{2}{|c|}{ Multiple choice items ( $n=5)$} & \multicolumn{2}{|c|}{ Multiple choice items ( $n=8$ ) } \\
\hline Max. possible score & \multicolumn{2}{|c|}{50} & \multicolumn{2}{|c|}{40} \\
\hline Mean & 39.49 & 37.40 & 27.50 & 28.93 \\
\hline SD & 13.41 & 16.26 & 10.97 & 11.71 \\
\hline $\begin{array}{l}\text { No. of participants taking both pre- } \\
\text { and post-quizzes }\end{array}$ & \multicolumn{2}{|c|}{38} & \multicolumn{2}{|c|}{28} \\
\hline Mean & 41.84 & 40.53 & 30.71 & 27.86 \\
\hline SD & 12.49 & 14.13 & 6.77 & 13.01 \\
\hline No. of students with higher score & \multicolumn{2}{|c|}{$10(26.32 \%)$} & \multicolumn{2}{|c|}{$12(42.86 \%)$} \\
\hline No. of students with same score & \multicolumn{2}{|c|}{$15(39.47 \%)$} & \multicolumn{2}{|c|}{$5(17.86 \%)$} \\
\hline No. of students with lower score & \multicolumn{2}{|c|}{$13(34.21 \%)$} & \multicolumn{2}{|c|}{$11(39.29 \%)$} \\
\hline
\end{tabular}

Given the year-long pilot study, not all the 200 participants managed to complete the two quizzes in the pre- and post-setting; nor did they finish all the listening and reading modules. A marked fall in the post-quiz attempts is evident in the two language areas: only about $36 \%$ of the participating students took the postquiz (Table 3). Closer inquiry of the data reveals a further drop in numbers concerning students who completed both quizzes on the same task. Listening $(n=28)$ suffered a greater loss than reading $(n=38)$ in 
terms of participation in both quizzes. Analysis of the quiz performance of these 66 students follows next. Data from the focus group interviews and online survey serve to triangulate the analysis for internal consistency.

Of those who completed both pre- and post-quizzes (Table 3), about 66\% (reading) and 61\% (listening) recorded either improved or stable performance. It is worth noting, however, nearly $34 \%$ and $39 \%$ of the students scored lower in the reading and listening post-quizzes respectively. As seen in Figure 3, over half of the 38 students ( $n=20$ in pre; 21 in post) registered a score range between 41 and 50 on both reading quizzes, whereas many of the 28 students in the pre- $(n=12)$ and post-listening quizzes $(n=15)$ scored between 31 and 40 . This contrasted sharply with a noticeable fall in the post-quiz reading score for those ( $n=11$ in pre; 7 in post) in the 31-40 range, and in the 21-30 score category for the listening post-quiz ( $n=13$ in pre; 5 in post). The decrease in the latter seems to match a corresponding jump from zero to five students in the 0-10 score category.

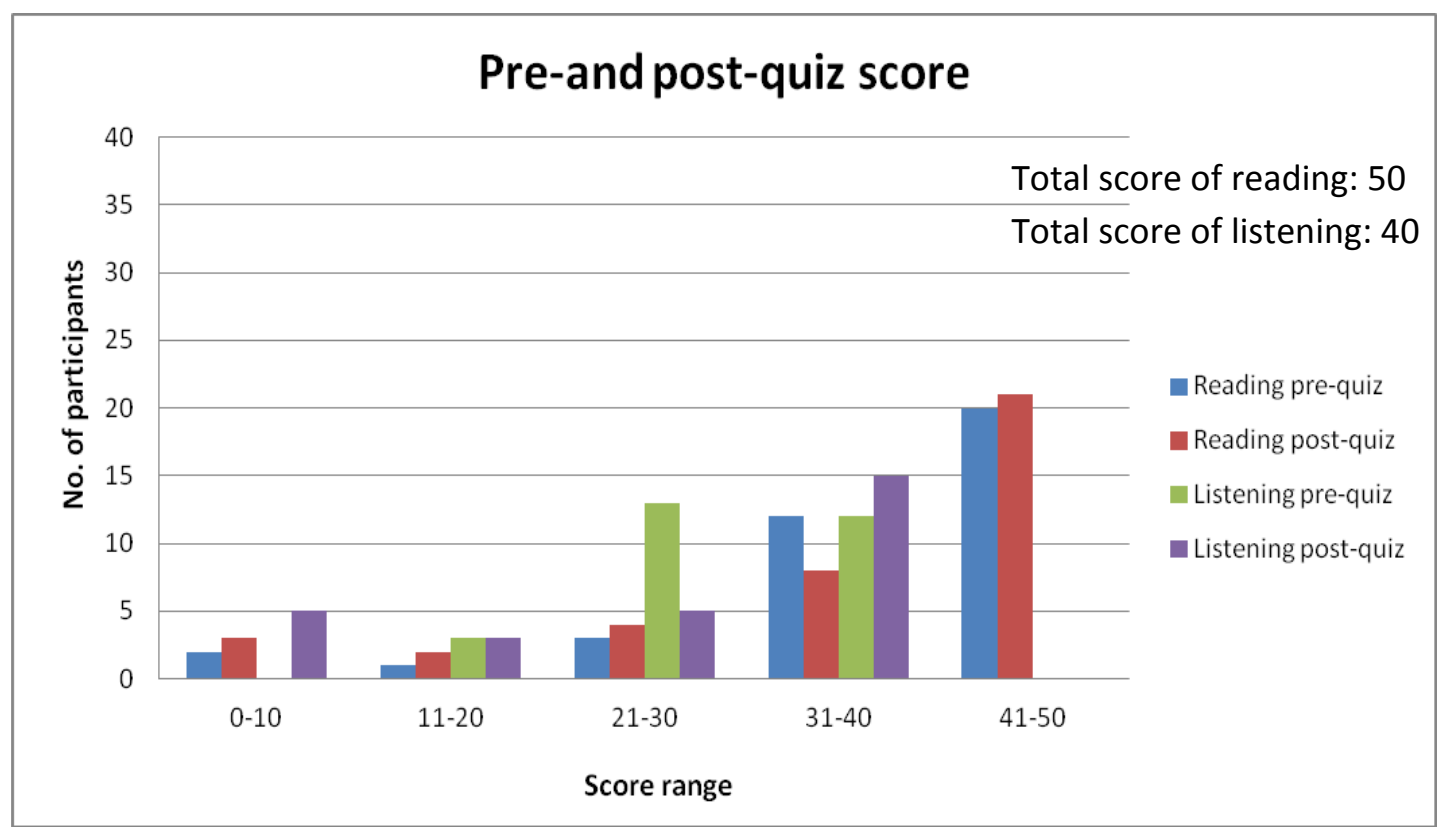

Figure 3. Distribution of score range and number of participants

To determine the difficulty level of the questions, a feature available on the Blackboard's 'Grade Center' was deployed for item analysis, where the number of correct answers given by students was divided by the total number of participating students. From this, questions with a correct rate of over $80 \%$ would be classified as 'easy', 30\% - 80\% 'medium', and less than $80 \%$ 'hard'. The three difficulty levels and the constructs measured for each question are displayed in Table 4.

Table 4. Difficulty level of quiz questions and construct measured 


\begin{tabular}{|l|l|l|l|}
\hline Question & Reading - Banking policy in Spain & $\begin{array}{l}\text { Difficulty } \\
\text { level }\end{array}$ & $\begin{array}{l}\text { *Construct } \\
\text { measured }\end{array}$ \\
\hline 1 & What has the government done to make mergers like this possible? & medium & R1,R2, R5 \\
\hline 2 & $\begin{array}{l}\text { With the merger completed, CaixaBank will be the largest in all BUT } \\
\text { which of the following regions? }\end{array}$ & medium & R3, R4 \\
\hline 3 & Why does the bank say this merger is necessary? & medium & R5, R6 \\
\hline 4 & What are the current government's projections for 2012? & medium & R2, R3, R7 \\
\hline 5 & What is significant about Spain's unemployment rate? & medium & $\begin{array}{l}\text { R1, R4, R5, } \\
\text { R7 }\end{array}$ \\
\hline Question & Listening - Cyber security & $\begin{array}{l}\text { Difficulty } \\
\text { level }\end{array}$ & $\begin{array}{l}\text { *Construct } \\
\text { measured }\end{array}$ \\
\hline 1 & $\begin{array}{l}\text { According to a recent UK government study, how much does cyber } \\
\text { crime cost the UK economy? }\end{array}$ & medium & L4 \\
\hline 2 & According to the recording, many computer hackers are: & easy & L3 \\
\hline 3 & How is cyber crime different from traditional crime? & medium & L3, L4 \\
\hline 4 & What is a botnet? & medium & L2 \\
\hline 5 & You hear the word 'malicious' in the recording. What does it mean? & medium & L2 \\
\hline 6 & $\begin{array}{l}\text { The UK government is planning to spend } £ 650 \text { million on improving } \\
\text { cyber security. According to John Bassett from the Royal United } \\
\text { Services Institute, what should be the first priority? }\end{array}$ & medium & L4, L5 \\
\hline 7 & What did you learn about the word 'espionage' in the recording? & medium & L1, L2 \\
\hline 8 & What is the meaning of 'espionage'? & medium & L1, L2 \\
\hline
\end{tabular}

Key: Construct measured (see also Table 1)

\subsubsection{Reading}

According to Figure 4, 10 of the 38 students who took both the pre- and post-reading quizzes scored higher in the post-quiz. Of these, two students with a zero score in the pre-quiz achieved considerable progress in their second attempt: one obtained 40 and another 50 out of a maximum score of 50 . The performance of 15 students remained unchanged. A decline in the post-quiz score was reported for 13 students. A mild decrease of the reading quiz mean from 41.84 (pre) to 40.53 (post) is shown in Table 3. 


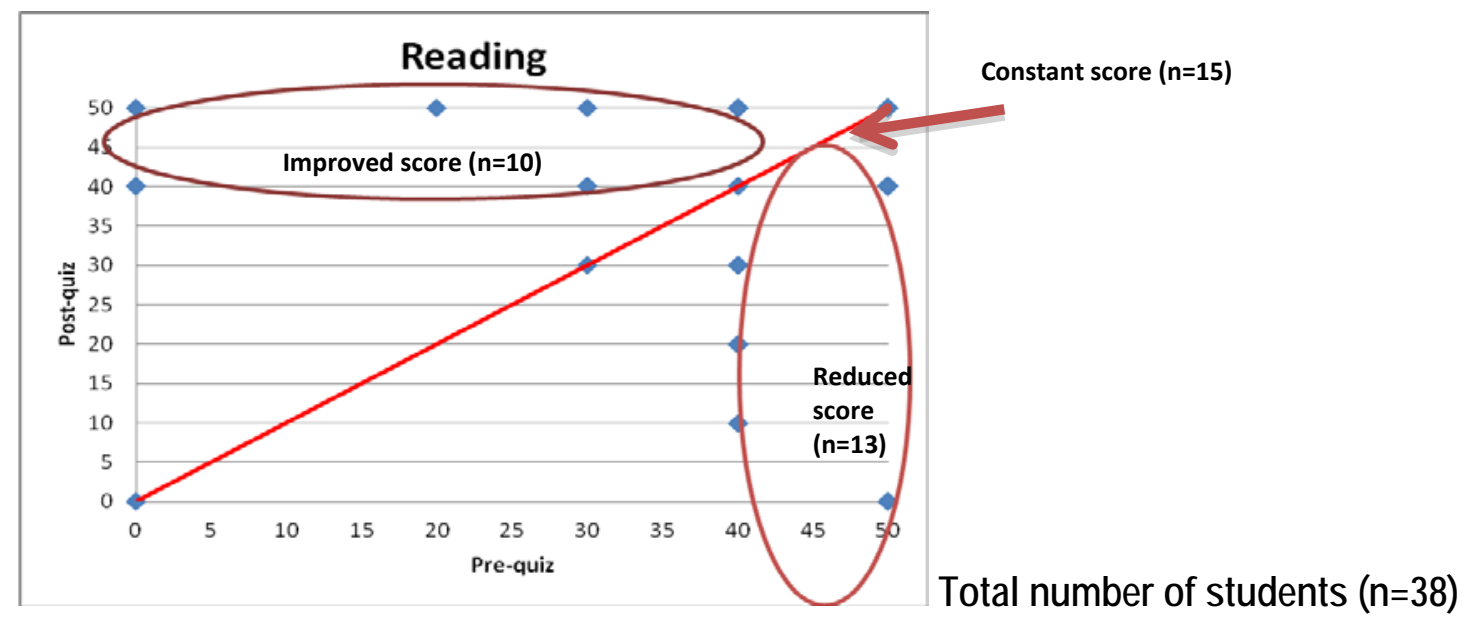

Figure 4. Reading quiz raw scores

We conjecture two key non-linguistic contributing factors to the outcome. Competing demands for students' time and energy due to course assignment deadlines over the post-quiz period might have lessened interest and attention. Some students could also have misconstrued the small number of questions $(n=5)$ for the reading quiz as easy, hence clicking the 'submit' button without careful checking. The lower post-quiz mean might be an indication of some students being less careful monitors of their output in their second attempt than in the first, rather than a reflection of their reading ability. The highest incorrect rate - $26.3 \%$ (pre) and $28.9 \%$ (post) - was recorded for question 3 (of 'medium' difficulty).

Question $3=$ Why does the bank say this merger is necessary?

While a host of factors might affect reading comprehension, it is widely recognised that effective reading correlates strongly with lexical and grammatical knowledge to construct local and global coherence and to unpack textual meaning (Zhang, 2012). The reading text for the quiz examined Spain's banking policy after the property market bubble, an extract from the BBC business news. Question 3 aimed to measure two main reading skills: inferring the writer's reasoning (R5) and interpreting an attitude or intention of the writer (R6). Most students thought mistakenly the purpose of the merger was 'to allow Spain to compete with other countries', or 'to prevent massive layoffs', failing to see the government's effort 'to stabilise Spain's shaky economy' as the main reason for the move.

We can speculate that topical relevance or familiarity with the subject of banking might be an issue, compounded by terms such as 'merger', 'consolidate', 'contracted', and 'austerity cuts'. This could have posed comprehension difficulty for learners without prior knowledge or training in business or economics, as confirmed by prior study (Zhang, 2012.). As researchers into reading skills pedagogy like Maley and Prowse (2013) and Mishan and Timmis (2015) note, reading, be it print- or screen-based, involves a complex, interrelated set of processes to decode messages by means of microskills (bottom-up process at the level of morphemes and single words, syntax and discourse), and macroskills (top-down process to infer meaning from a given linguistic, cultural or social context, and to map such inferences onto one's 
interiorised schemata to make sense of the whole). Where access to these skills is curtailed, text decoding efforts can be thwarted.

This view is given support by an engineering student (focus group interview) who admitted to feeling 'frustrated' as a result of his non-business background:

This article was really difficult to understand... I got some parts wrong because...I didn't understand some of the words...they were very technical words...so I randomly chose one...the wrong answer.

Another engineering student (focus group interview) expressed similar sentiment:

I got confused by the percentages shown in the passage... the passage was about expense budget...it seems very different from what I know, and I'm not very interested in economic investment.

This student (focus group interview) complained about the content of the article:

I know very little about Spain...or its bank...we don't talk about this ...In my secondary school, we studied things about Hong Kong... like housing, education...I could do better if I knew the topic.

However, some students (focus group interview) noted several virtues of online reading activities that could have explained their improved reading performance:

Yes, the reading quiz was difficult...but I managed to finish it because I did it at home...the environment is very relaxing and between quizzes I could give myself a rest, which is good.

(non-threatening atmosphere; flexibility; learner control)

I could re-read the answers while working on the reading quiz, search the internet and read the questions again before answering...I also went online and checked related articles...like "something decreased or decreased by or decreased to"...still I got the answer wrong... mixed up the prepositions. Some online articles have animation, interesting pictures, and sound. More fun than reading paperbooks.

(enhanced reading interest through multimodal texts; greatly amplified reading experience; access to an expanded range of internet resources)

\subsubsection{Listening}

A total of 28 students completed both the pre- and post-listening quizzes. Improved quiz scores of between 10 and 15 were recorded for 12 students. Five maintained the same score, but 11 performed less well in the post-quiz, with a decrease in scores ranging from 5 to 35 (Fig. 5). The mean also dropped from 30.71 (pre) to 27.85 (post-quiz) (Table 3). 


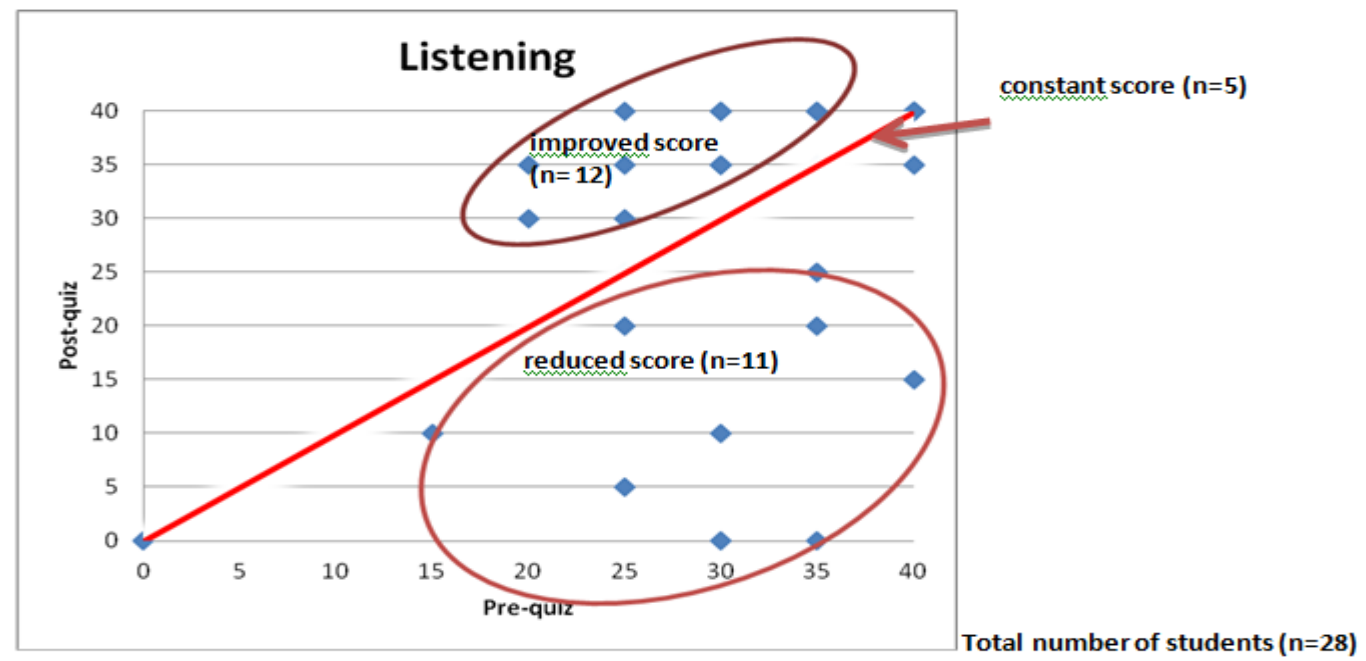

Figure 5. Listening quiz raw scores

It needs to be emphasized that the small number of participants $(n=28)$ could have skewed the findings. Still, the online listening quizzes have yielded some noteworthy results. Question 8 incurred the highest incorrect rate (46.4\%) in both quizzes. The second highest incorrect rate was identified for question 5 in the pre-quiz (42.9\%), and question 7 (39.3\%) in the post-quiz. All three questions entailed an understanding of a specific word in context: 'espionage' (questions 7 and 8), and 'malicious' (question 5). Questions 7 and 8 aimed to gauge students' ability to identify specific information (L1) and to interpret a word or phrase used by the speaker (L2). Question 5 focused mainly on L2.

Question $5=$ You hear the word 'malicious' in the recording. What does it mean? Question $7=$ What did you learn about the word 'espionage' in the recording? Question 8 = What is the meaning of 'espionage'?

Answers to questions 7 and 8 varied: from erroneous ones such as 'curriculum' and 'cyber security' (question 7), to 'the crime of intentionally starting a fire' and 'civic education programme' (question 8). Research into second language listening confirms the correlation between adequate levels of speech decoding and word recognition and listening comprehension ability, where vocabulary knowledge seems a reliable predictor of listening abilities (Matthews \& Cheng, 2015). Lexical familiarity and awareness of phonological features like blurred word boundaries, varied intonation patterns and speaker accent are also found to affect listening comprehension (Mishan \& Timmis, 2015). In this case, 'espionage' is unlikely to be a term Hong Kong (Chinese) students might often encounter, aurally or textually, in their daily life, thus their failure to identify the correct answer. For question 5, instead of selecting 'intended to harm or upset other people' to explain 'malicious', many chose 'clever in a complicated way', 'famous for something bad', or even 'delicious maltesers'. This can be accounted for by a student comment (focus group interview): 
This word ['espionage'] sounds strange... it's hard to guess what it means...I chose one that looks like the correct answer...but got it wrong.

Despite having the lowest number of participants, listening was nominated by several students (focus group interview) as the most important skill and quiz. Of note is a student remark showing pride in his ability to distinguish between British and American accent because of his frequent exposure to and interest in online BBC 6 Minutes English (extracts used in the listening quiz) and TED talks:

I remember that the recording was from the BBC English news...I think it's English Six minutes or something like that. So the English [British] accent was easy...I don't think it's a challenge for me although I still got one [question] wrong...so after this quiz, I also search for some other BBC 6 minute English online programmes to listen to... TED talks are my favourite too... but more American accent.

Another student reported affective resonance with the context:

I enjoyed the listening because it is very similar to the news l've heard on the BBC. It talks about the UK government and UK economy at the end, and that's why I enjoyed it.

A third student recounted devising her own listening strategies:

I played the audio two times. But before that, I read the questions and made sure I had an idea what the audio was about... then I would listen to the audio at least two times. After the first listening, if I'm sure what's the answer, I will choose the answer; but if I'm not sure I will leave it, and then during the second listening I will look through again... and I would also google words I don't understand instantly, especially the slang... easier to do online.

The above student remarks (focus group interview) show students' recognition of the value of the opportunities afforded for independent listening on the internet: some resources target English learners of different proficiency levels; others offer authentic listening materials for enjoyment and/or instruction, with visual and textual support to render possible contextualized comprehension for language development to flourish.

3.2 Objective 2: to identify key challenges associated with online language learning at university and possible ways to address them

Findings from the pilot study suggest four challenges that can impinge on the design and delivery of online language learning: online materials development, student motivation, technology-pedagogy interface, and linguistic knowledge and beyond.

\subsubsection{Online materials development}


Section 2.2 has described the online language materials specifically developed to hone students' English reading and listening skills. The pre- and post quizzes act as an important pedagogic device that helps identify priority areas for learning and completion. The results of an online questionnaire survey $(n=175$, Fig. 6), administered near the end of the pilot study, indicate particular student appreciation (over $80 \%$ agreement) in the areas of additional hyperlinked learning sources, variety and appropriateness of online materials. Although around $70 \%$ agreed that the online activities helped boost confidence and motivation and were clear in their visual presentation, there was notable disagreement about the clarity of the visual presentation (28\%) and increased confidence resulting from the online materials (21\%).

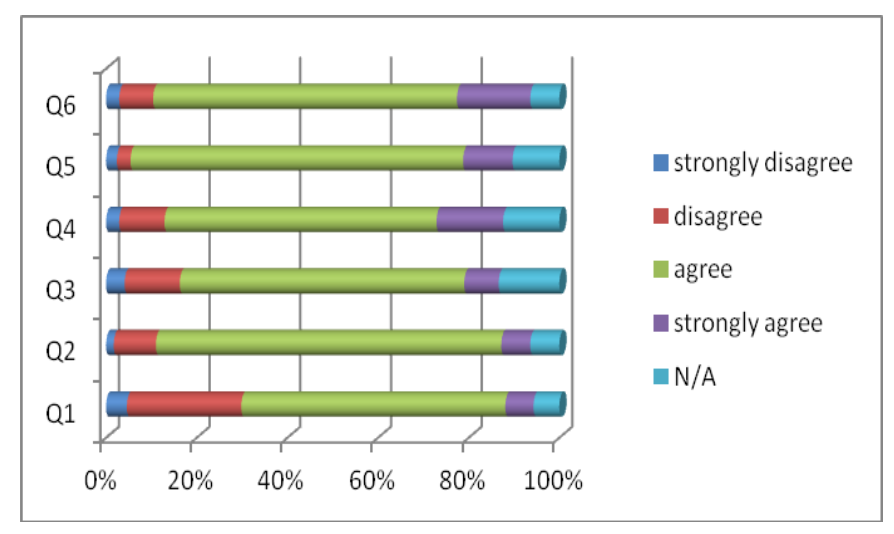

Key:

Q1. The online learning activities help to increase my confidence in using English.

Q2. The difficulty level of the online learning materials is about right.

Q3. The presentation of the input can help me focus on the learning point(s).

Q4. Bite-sized learning, aided by the time indicators, has helped to sustain my motivation in completing the modules.

Q5. The hyperlinks to additional language practice are related to the focus of each module.

Q6. There is a variety of online learning materials.

Figure 6. Online Questionnaire Survey Results $(n=175)$

Student dissatisfaction with the visual presentation seems to stem from the difficulty of navigating the user interface ('I don't want to go to another page and do so many clicks...not many functions to use'), and the use of graphics ('Graphics don't attract me, because I think as age increases, the attractiveness of those kinds of things decreases'; It'd be better if pictures or drawings could be integrated... because too many words would be boring for me') (focus group interview).

Favourable remarks about self-perceived language improvement and confidence during the focus group interviews are consistent with findings in other OLL studies (e.g., Hsu et al., 2013; Lysenko \& Abrami, 2014). They, however, appear to contradict the online survey results. This points to a major challenge inherent in online materials development - that of addressing diverse stakeholder interests, abilities, and perceptions, among others. Although the apparently intuitive nature of materials development is well documented (Prowse, 2011), Hadfield (2014) contends that intuition should not be misconstrued as an absence of a principled approach. She emphasizes that most experienced materials developers work with a tacit set of principles that takes account of, for instance, end-users' viewpoints and the context in which the materials are understood and used. From recent OLL research (e.g., Kervin \& Derewianka, 2011; 
Meskill, 2013), five recurring features identified as central to online materials design have surfaced: a) expandability; b) relevance and accessibility; c) feedback provision; d) potential to stimulate and sustain motivation, and e) scaffolding for independent learning.

To tackle this challenge, our next phase of OLL development will be expanded to include online language activities targeting grammar, vocabulary, general speaking skills (pronunciation, stress and intonation), as well as workplace oral communication skills (interview techniques). Such activities will be divided into two levels of difficulty (average and above-average) as determined by six key factors that are likely to affect the time and effort required for task processing. These factors pertain to the complexity of the sentence structure; the difficulty level of the vocabulary; the length of the reading text, sentences or the listening file; students' prior knowledge; the cognitive demand of the tasks; and the amount of information to be processed. A variety of task types to be included range from fill-in-the -blank, true or false statement, short answer, multiple answer, matching, multiple choice, open-ended answer and recorded responses. Explanatory notes on correct and incorrect answers to support learner autonomy will also be provided. Underpinning the above is "flexible responsiveness" where OLL activities are "linearly and cumulatively designed" (Meskill \& Anthony, 2010: 187), and are characterized by time-sensitive chunks of input to enhance the amount and quality of student participation for optimal learning.

\subsubsection{Student Motivation}

Table 3 shows a considerable decline in participant number in the post-quiz, a period that coincided with deadlines for course assignments at university. Withdrawal of interest and lack of time on students' part could have accounted for the phenomenon, as confirmed by student responses (focus group interview). Where priorities are usually accorded to credit-bearing subjects, it is no surprise for non-mandatory programmes such as our pilot study to suffer diminishing participation. Added to this might be that initial enthusiasm about online language learning could wane over time, prompting a less robust view of the activities as predictable and pedestrian, hence reduced engagement (online survey, Fig. 6). A student (focus group interview) referred to her OLL experience metaphorically as a 'beautiful deep blue sea' and a 'buffet' (vast learning resources), but she reported feeling lost and confused (lack of direction). 'Blue', according to the student, could also evoke 'depressed' feelings. It can be inferred, therefore, that OLL is often subject to the vagaries of individual idiosyncrasies.

We have decided to examine two possible ways to maintain motivation. The first is to know and understand the students to appreciate better their needs, goals and aspirations. This can be achieved through user walkthroughs, as evidence (Hemard, 2003) shows that walkthroughs can help students articulate their needs, or reveal needs they are not even aware of. Information about students' reactions to the computer, the system, the interface, or the task design, holds promise of enhancing the pedagogical validity of interactions for greater engagement. On a practical level, a reward system will be devised to differentiate levels of student achievement, where points accrued from the online language activities enable students to progress from one tier to the next and to the top. In one sense, this element of competition sets 
up a learning environment that mimics the gaming or virtual worlds with reported benefits of sustaining student interest (Sykes \& Reinhardt, 2013).

To this end, we have received university funding to develop an English language game-mediated app, with a focus on providing vocabulary and grammar practice in contextualized language use, where meaning and form are addressed in tandem. There will be different levels of progress, and, according to the scores a student attains, the app directs her or him to the relevant online grammar or vocabulary activities for additional practice, before proceeding to the next level. The app will also feature player ranking that has the potential to establish a structure of benign competition for learning English in a non-threatening atmosphere. Findings on the effect of the app on student learning will be reported in a future article.

\subsubsection{Pedagogy-technology interface}

A major student concern (focus group interview) pertained to that of limited interface options (online survey, Fig. 6). The paradigm in a learning management system, like Blackboard, puts emphasis on linking and uploading information that focuses on passive reception of knowledge (Godwin-Jones, 2003). This appears to contradict the contemporary goal of education to nurture seekers with knowledge-transforming capacity. Language learning, as a layered, intricate process, is often constrained by the limited functionality in the learning management system to tap into the full potential of the medium. Further, the default structure of such a system tends to regard internet resources as fixed, immutable categories, thus inadvertently predisposing teachers to the mindset of the software developers that teachers can only use the available functions and tools in the system. In other words, technological tools can restrict teachers' ability to devise innovative language tasks. An observation by a student (focus group interview) likened OLL to a 'baby': 'it must improve..., to grow, to be more sophisticated...so that he can meet more people and develop his life... I think OLL is worth developing.'

Apparently, there are obstacles to creating new paradigms for OLL in the short term, some easily tackled, others less so. One option which we are considering is inter-institutional collaboration, making common cause with language practitioners, for a more persuasive funding application in the form of shared materials development and exchange of expertise and experience, to create a broader canvas to move OLL forward. A further option is to adopt a parallel process of research and OLL pedagogy. Research aims to uncover findings conducive to an enhanced understanding of the effectiveness of the materials, the appropriateness or otherwise of the language competences achieved, and the tools and resources available to generate a wider and more attractive array of learning options. Informed by research data, OLL pedagogy can better monitor levels of success and limitations for which revision might be desirable and necessary.

\subsubsection{Linguistic knowledge and beyond}


While intimating the pleasure of individual choice and freedom in OLL, several students expressed a desire to interact with others (focus group interview), which is palpable given the proliferation of social networking sites. Opportunities afforded by social networking technology intersect with the way in which these tools are employed to mediate language learning, destabilizing the border between formal and informal learning, and between learning partnerships of culturally varied groups. Emanating from this is increasing interest in intercultural communicative competence that adopts a perspective of OLL as a participatory process (Mollering \& Levy, 2012). Such a perspective carries implications for pedagogical decisions that could decentre linguistic knowledge, and centre instead on sociocultural and discursive practices that see students as members of groups. The position raises challenges about how language learners can be scaffolded as they make the transition from a sheltered institutional learning context to an open real-world setting such as public Internet discussion forums, in which reciprocal interaction can problematize meaning negotiation and conflicting beliefs and value systems.

'OLL is like a puzzle,' observed a student (focus group interview), where the fun part was the sense of achievement when all the pieces fell in place. The metaphor alludes to OLL involving components that are fluid, shifting, and how the jigsaw pieces mesh with one another resembles to some degree the myriad ways in which participants in an online community produce coherent exchanges. Teachers can take inspiration from other studies that provide opportunities for cognitively challenging, meaningful use of language. As an example, Galloway and Rose (2014) reported a success story of using listening journals to heighten awareness of World Englishes by drawing on internet-based resources, and creating their own digital audio and video recordings of speakers from different countries. An additional option would be for teachers to develop tasks that might involve students visiting the Facebook page of a celebrity figure to examine the various texts and talks on the page. From this, students can be instructed to identify differences in language use in order to construct background knowledge about the writers and readers of the page. This cultural dimension constitutes an important focus in the next stage of our study.

\section{Conclusions and Limitations}

The pilot study has augmented to some extent our understanding of Hong Kong (Chinese) university students' OLL experience, albeit the highly tentative findings. Evidence from the pilot study has corroborated prior findings in several respects. OLL has the merit of stimulating motivation and engagement, pushing students to explore internet-based resources for language learning, while causing confusion to some due to the enormity of the available resources. There is also evidence that hints at a range of individual variation that needs to be accommodated for effective OLL to occur. Four challenges, namely, online materials development, student motivation, pedagogy-technology interface, and linguistic knowledge and beyond, arising from OLL have been identified, and possible options to address them suggested. Two main limitations of the study warrant mention. One limitation concerns the small number of participants and the specific focus on students' English reading and listening performance in the pre- and post-quizzes, and the limited question types and numbers due to time constraints. Fuller accounts of students' interaction with other online activities might have furnished a more comprehensive picture of the OLL experience. A second limitation relates to the choice of instruments for data generation and analysis. Additional data from user walkthroughs and user self-reports would illuminate further the micro-aspects of OLL that are widely recognized as subjective and personal. Although it is our purpose to understand Hong 
Kong (Chinese) university students' OLL experience, data from different learner populations (e.g., university students in China, Taiwan and Singapore) may permit more sturdy conclusions to be drawn. None the less, a worthy message from the study is that as a vital condition for success, OLL needs to be predicated on a tripartite framework emcompassing hardware (technology), software (pedagogy), and humanware (stakeholders).

\section{Acknowledgements}

We gratefully acknowledge funding support from the Teaching Development Grants of the Hong Kong Polytechnic University for this project. Very special thanks go to the project team - Dr Viola Wong, Miss Tracy Luo, and Ms Polly Chan - for their incredible professionalism, and to the participating students for their candid comments. We also express our gratitude to the reviewers for their time and valuable suggestions.

\section{References}

Al-Musalli, A.M. (2015). Taxonomy of lecture note-taking skills and sub-skills. International Journal of Listening, 29(3), 134-147.

Amaral, L.A. \& Meurers, D. (2011). On using intelligent computer-assisted language learning in real-life foreign language teaching and learning. ReCALL, 23(1), 4-24.

Blake, R. J. (2011). Current trends in online language learning. Annual Review of Applied Linguistics, 31, 19-35.

Chang, M.M. (2007). Enhancing web-based language learning through self-monitoring. Journal of Computer Assisted Learning, 23, 187-196.

Chau, J. \& Lee, A. (2014). Technology-enhanced language learning (TeLL): An update and a principled framework for English for Academic Purposes (EAP) courses. Canadian Journal of Learning and Technology, 40(1), 1-24.

Author ${ }^{2}, \mathrm{Wu}, \mathrm{W}$, Author $^{1}$, \& Lughmani, S. (2012). ESL readers' comprehension performance: The Chinese secondary context. English Language Teaching Journal, 66(3), 304-317.

Galloway, N. \& Rose, H. (2014). Using listening journals to raise awareness of global Englishes in ELT. English Language Teaching Journal, 68(4), 386-396.

Godwin-Jones, R. (2003). Optimising web course design for language learners. In U. Felix (Ed.), Language learning online: Towards best practice (pp.43-56). Lisse: Swets \& Zeitlinger.

Goh, C.C.M. (2013). ESP and reading. In B. Paltridge \& S. Starfield (Eds.), The handbook of English for specific purposes (pp.55-76). DOI:10.1002/9781118339855

Hadfield, J. (2014). Chaosmos: Spontaneity and order in the materials process. In N. Harwood (Ed.), English language teaching textbooks: Content, consumption, production (pp.320-360). Basingstoke: Palgrave Macmillan.

Hemard, D. (2003). Language learning online: Designing towards user acceptability. In U. Felix (Ed.), Language learning online: Towards best practice (pp.21-42). Lisse: Swets \& Zeitlinger. 
Hirvela, A. (2013). ESP and reading. In B. Paltridge \& S. Starfield (Eds.), The handbook of English for specific purposes (pp.77-94). DOI:10.1002/9781118339855

Hsu, C., Hwang, G., Chang, Y., \& Chang, C. (2013). Effects of video caption modes on English listening comprehension and vocabulary acquisition using handheld devices. Educational Technology \& Society, 16(1), 403-414.

Hung, S. A. \& Huang, H.D. (2015). Blogs as a learning and assessment instrument for English-speaking performance. Interactive Learning Environments, DOI: 10.1080/10494820.2015.1057746

Kervin, L. \& Derewianka, B.(2011). New technologies to support language learning. In B. Tomlinson (Ed.), Materials development in language teaching ( $2^{\text {nd }} \mathrm{ed}$.) (pp.328-351). Cambridge: Cambridge University Press.

Li, H. \& Suen, H.K. (2013). Detecting native language group differernces at the subskills level of reading: A differential skill functioning approach. Language Testing, 30(2), 273-298.

Lysenko, L.V. \& Abrami, P.C. (2014). Promoting reading comprehension with the use of technology. Computers \& Education, 74, 162-172.

Maley, A. \& Prowse, P. (2013). Reading. In B. Tomlinson (Ed.), Applied linguistics and materials development (pp.165-182). London: Bloomsbury.

Matthews, J. \& Cheng, J. (2015). Recognition of high frequency words from speech as a predictor of L2 listening comprehension. System, 52, 1-13.

Meskill, C. (Ed.) (2013). Online teaching and learning: Sociocultural perspectives. London: Bloomsbury.

Meskill, C. \& Anthony, N. (2010). Teaching languages online. Bristol: Multlingual Matters.

Mishan, F. \& Timmis, I. (2015). Materials development for TESOL. Edinburgh: Edinburgh University Press.

Mollering, M. \& Levy, M. (2012). Intercultural competence in computer-mediated-communication: An analysis of research methods. In M. Dooly and R. O'Dowd (Eds.), Researching online foreign language interaction and exchange: Theories, methods \& challenges (pp.233-264). Bern: Peter Lang.

Murphy, P. (2007). Reading comprehension exercises online: The effects of feedback, proficiency and interaction. Language Learning \& Technology, 11(3), 107-129.

Pasfield-Neofitou, S. (2014). Language learning and socialization opportunities in game worlds: Trends in first and second language research. Language and Linguistics Compass, 8(7), 271-284.

Prowse, P. (2011). How writers write: Testimony from authors. In B. Tomlinson (Ed.), Materials development in language teaching ( $2^{\text {nd }}$ ed.) (pp.151-73). Cambridge: Cambridge University Press.

Skyes, J.M. \& Reinhardt, J. (2013). Language at play: Digital games in second and foreign language teaching and learning. Boston: Pearson.

Wible, D., Liu, A.L.E. , \& Tsao, N.L. (2011). A browser-based approach to incidental individualization of vocabulary learning. Journal of Computer Assisted Learning, 27, 530-543.

Zhang, D. (2012). Vocabulary and grammar knowledge in second language reading comprehension: A structural equation modeling study. The Modern Language Journal, 96(4), 558-575. 


\section{Appendix}

\section{Student Focus Group Interview}

Please take a moment to consider your response to the following questions. You may make notes. Feel free to share with us your thoughts. If you have nothing to say, it's fine. Just tell us.

Perceived usefulness:

1. Did the online language activities help to increase your confidence in using English? In what way? Can you say a few words about this?

2. Did the online language activities stimulate your interest in learning English? How? Can you explain a bit more?

3. Did the online language activities help to improve your English? Which area? In what way?

4. Was the level of difficulty of the language activities about right?

5. Do you think there was a sufficient range of language activities? If not, what other language activities would you like to see?

Ease of navigability:

6. Was it easy to navigate between different sections of the online activities?

7. Did the presentation of input help you focus on learning point(s)?

8. Was it easy to move between the hyperlinks and the language activities? Any suggestions?

9. Did the graphics help to stimulate interest in the online activities?

\section{Attitudinal Change}

10. Will you continue to learn English through online language activities?

11. What is your view on online language learning?

To wrap up the interview, please complete this...

Online language learning is like... 